\title{
Article
}

\section{Morphine self-administration alters the expression of translational machinery genes in the amygdala of male Lewis rats}

Ucha, Marcos, Coria, Santiago M, Núñez, Adrián E, Santos, Raquel, Roura-Martínez, David, Fernández-Ruiz, Javier, Higuera-Matas, Alejandro and Ambrosio, Emilio

Available at http://clok.uclan.ac.uk/27967/

Ucha, Marcos, Coria, Santiago M, Núñez, Adrián E, Santos, Raquel ORCID: 0000-0003-3129-6732, Roura-Martínez, David, Fernández-Ruiz, Javier, Higuera-Matas, Alejandro and Ambrosio, Emilio (2019) Morphine selfadministration alters the expression of translational machinery genes in the amygdala of male Lewis rats. Journal of Psychopharmacology, 33 (7). pp. 882893. ISSN 0269-8811

It is advisable to refer to the publisher's version if you intend to cite from the work. http://dx.doi.org/10.1177/0269881119836206

For more information about UCLan's research in this area go to http://www.uclan.ac.uk/researchgroups/ and search for <name of research Group>.

For information about Research generally at UCLan please go to http://www.uclan.ac.uk/research/

All outputs in CLoK are protected by Intellectual Property Rights law, including Copyright law. Copyright, IPR and Moral Rights for the works on this site are retained by the individual authors and/or other copyright owners. Terms and conditions for use of this material are defined in the policies page. 


\section{Morphine self-administration alters the expression of translational machinery genes in the amygdala of male Lewis rats}

Marcos Ucha ${ }^{1}$, Santiago M Coria ${ }^{1}$, Adrián E Núñez ${ }^{2}$, Raquel Santos-Toscano ${ }^{1,3}$, David RouraMartínez ${ }^{1}$, Javier Fernández-Ruiz ${ }^{4}$, Alejandro Higuera-Matas ${ }^{1^{*}}$ and Emilio Ambrosio ${ }^{1^{*}}$

\section{Marcos Ucha}

(Department of Psychobiology, School of Psychology) UNED, Madrid, Spain.

\section{Santiago M Coria}

(Department of Psychobiology, School of Psychology) UNED, Madrid, Spain.

\section{Adrián E Núñez}

(Laboratorio de Neuropsicología de las Adicciones, Instituto de Neurociencias) Universidad de Guadalajara, México.

\section{Raquel Santos-Toscano}

(Department of Psychobiology, School of Psychology) UNED, Madrid, Spain; (School of Pharmacy and Biomedical Sciences) University of Central Lancashire, Preston, United Kingdom.

David Roura-Martínez

(Department of Psychobiology, School of Psychology) UNED, Madrid, Spain.

\section{Javier Fernández-Ruiz}

(Instituto Universitario de Investigación en Neuroquímica, Departamento de Bioquímica y Biología Molecular) Facultad de Medicina, Universidad Complutense; CIBER de Enfermedades Neurodegenerativas (CIBERNED); Instituto Ramón y Cajal de Investigación Sanitaria (IRYCIS), Madrid, Spain

\section{Alejandro Higuera-Matas}

(Department of Psychobiology, School of Psychology) UNED, Madrid, Spain. *Joint senior authorship

\section{Emilio Ambrosio}

(Department of Psychobiology, School of Psychology) UNED, Madrid, Spain. *Joint senior authorship

\section{Correspoding author:}

Alejandro Higuera-Matas, Department of Psychobiology. School of Psychology. UNED. C/Juan del Rosal 10, 28040, Madrid, Spain.

Email: ahiguera@psi.uned.es 


\section{Abstract}

Background: Addiction is a chronic disorder with a high risk of relapse. The neural mechanisms mediating addictions require protein synthesis, which could be relevant for the development of more effective treatments. The mTOR signaling pathway regulates protein synthesis processes that have recently been linked to the development of drug addiction.

Aims: To assess the effects of morphine self-administration and its subsequent extinction on the expression of several genes that act in this pathway, and on the levels of specific phosphoproteins (Akt, Gsk3 $\alpha / \beta, \mathrm{mTOR}$, PDK1 and p70 S6 kinase) in the amygdala, nucleus accumbens and the prefrontal cortex.

Methods: Male Lewis rats underwent morphine self-administration $(1 \mathrm{mg} / \mathrm{kg})$ for 19 days. They subsequently were submitted to extinction training for 15 days. Rats were killed either after self-administration or extinction, their brains extracted and gene expression or phosphoprotein levels were assessed.

Results: We found an increase in Raptor and Eif4ebp2 expression in the amygdala of rats that self-administered morphine, even after extinction. The expression of Insr in the amygdala of control animals decreased over time while the opposite effect was seen in the rats that selfadministered morphine.

Conclusions: Our results suggest that morphine self-administration affects the gene expression of some elements of the translational machinery in the amygdala.

Keywords: Morphine self-administration, Lewis rats, mTOR pathway, extinction, protein synthesis 


\section{1 - Introduction}

Addiction is a chronic debilitating condition with a high rate of relapse, for which there is no effective treatment (Kalivas and O'Brien, 2008; McLellan et al., 2000). The mechanisms underlying the shift from controlled recreational use of drugs to pathological compulsive behavior are not yet fully understood, nor are the long-lasting neuroadaptive changes behind the elevated risk of relapse.

The development of an addiction depends on synaptic plasticity, which in turn relies on protein synthesis (Kalivas and O'Brien, 2008; Kauer and Malenka, 2007; Lüscher and Malenka, 2011). Thus, a signaling pathway that has generated much interest of late is that involving the mechanistic target of rapamycin, mTOR, a serine/threonine kinase that plays an important role in different aspects of cell growth, proliferation and survival (Kwon et al., 2003; Pearce et al., 2010; Zhou et al., 2009). This protein nucleates two different multi-protein complexes known as mTOR complex 1 (mTORC1) and mTOR complex 2 (mTORC2). These complexes are part of a pathway which integrates many intracellular and extracellular signals, and regulates processes such as protein, lipid and nucleotide synthesis (Düvel et al., 2010; Ma and Blenis, 2004; Porstmann et al., 2008; Stoica et al., 2011), autophagy (Blommaart et al., 1995), mitochondrial metabolism (Cunningham et al., 2007; Schieke et al., 2006) and cytoskeletal organization (Sarbassov et al., 2004). Given its role in protein synthesis-dependent synaptic plasticity (Casadio et al., 1999; Costa-Mattioli et al., 2009; Liu-Yesucevitz et al., 2011; Stoica et al., 2011), this pathway is thought to participate in the neurobiology of addictions. Accordingly, several 
studies have focused on the effects of rapamycin, an inhibitor of mTOR activity, on addictive behavior.

These studies suggest that this signaling pathway is involved in the long-lasting neuroadaptations that occur as addictive disorders progress (Dayas et al., 2012; Neasta et al., 2014). For example, rapamycin was able to reduce a place preference for cocaine (Bailey et al., 2012; Wu et al., 2011) and amphetamine (Narita et al., 2005) when measured in a conditioned place preference (CPP) test (Wang et al., 2010). Systemic rapamycin injections also reduced motivation for self-administered cocaine in rats as measured in a progressive ratio schedule of reinforcement (James et al., 2016). In addition, there was a reduction in cue induced reinstatement of cocaine seeking mediated by mTOR effectors when rapamycin was injected directly in the core of the nucleus accumbens (NAcc) (Wang et al., 2010). Conversely, Mtor gene expression was down-regulated in the ventral striatum of relapse-prone rats (Brown et al., 2011). These results might seem conflictive, but the effects of rapamicyn found in the study of Wang were found only in the NAcc core, but not in the shell, while in Brown's study the whole ventral striatum was assessed. Also, it should be noted that gene expression is not necessarily related to protein activity, making the results of both studies difficult to compare.

Rapamycin also blocked nicotine-induced behavioral sensitization and activation of effectors of mTORC1 (Gao et al., 2014). It has also been suggested that the dopamine receptor $1 /$ mTOR complex 1-dependent plasticity is recruited following a first alcohol exposure and that it may be a critical cellular component of reinforcement learning (Beckley et al., 2016). In 
terms of opiates, chronic morphine decreases the soma size of dopaminergic cells in the ventral tegmental area (VTA), and neurotransmitter release by these cells, while increasing their excitability, events that are dependent on mTORC2 activity (Mazei-Robison et al., 2011). Activation of the mTOR pathway in the CA3 hippocampal region is necessary for the acquisition of morphine CPP in rats (Cui et al., 2010). Moreover, systemic inhibition of mTOR with rapamycin after re-exposure to a morphine paired compartment inhibits CPP in a dose dependent fashion, an effect that was replicated with cocaine and alcohol (Lin et al., 2014). Hence, mTOR may play a role in the reconsolidation of drug-paired memories. Elsewhere, a single dose of rapamycin was able to reduce the craving elicited by drug related cues in human heroin addicts (Shi et al., 2009).

To date, we are unaware of any study that has used a self-administration protocol to study the effects of opioids on the mTOR signaling pathway in rodents, so the objective of this study is to address this issue. Here, we assessed the effects of morphine self-administration, followed by extinction training, on the mTOR pathway in male Lewis rats. For this purpose, we chose three brain areas known for their involvement in opioid reinforcement and extinction learning: the amygdala, the NAcc, and the prefrontal cortex (PFC). The expression of several mediators of the mTOR pathway was analyzed using RT-qPCR. We chose three genes coding membrane receptors related to the pathway (Igf1r, Igf2 $r$ and Insr), seven genes coding upstream intracellular second messengers (Akt1, Akt2, Gsk3a, Gsk3b, Pdk1 and Pi3ca), three components of the mTOR complexes (Mtor, Rptor and Rictor) and seven downstream 
mediators and effectors of the pathway (Eef1a1, Eif4e, Rps6kb1, Rps6, Sgk1 and Eif4ebp2). Reviewing the functions and connections of all these genes is beyond of the scope of this paper; we recommend the excellent review of Laplante and Sabatini (2009) for further details. We have also assessed the levels of specific proteins encoded by these genes in western blots with phosphospecific antibodies directed to phosphorylation sites required for their activation by kinases of the pathway. The phosphoproteins assessed were Akt (Ser437), Gsk3 $\alpha / \beta$ (Ser21/9), mTOR (Ser2448), PDK1 (Ser241) and p70 S6 Kinase (Thr389).

\section{2 - Methods}

\section{1 - Animals}

Adult male Lewis rats (Charles River Laboratories) were housed in groups of $\mathbf{4}$ in plastic cages with wood chips bedding inside of a temperature and humidity controlled facility, and on a $12 \mathrm{~h} / 12 \mathrm{~h}$ light/dark cycle (lights on at $8: 00 \mathrm{am}$ ) with ad libitum access to food (standard commercial rodent diet A04/A03: Panlab) and water. Animals were allowed at least one week to acclimatize to the animal facility and they weighed around 250-300 $\mathrm{g}$ when the experimental procedures commenced. All the animals were maintained and handled according to European Union guidelines for the care of laboratory animals (EU Directive 2010/63/EU governing animal experimentation) and the Ethical Committee of UNED approved all the experimental procedures.

\section{2 - Experimental groups}


Animals were randomly assigned to the following groups: Morphine Self-administration (MSA), Vehicle Self-administration (VhSA), Morphine Extinction (MEx) and Vehicle Extinction (VhEx). Due to the limited number of operant boxes, several iterations of the selfadministration experiments with animals from each of the four groups were performed until a minimum of 8 subjects per group was obtained. Four animals were excluded from the experiment due to loss of the skull mount or catheter patency issues.

\section{3 - Apparatus}

Twelve operant conditioning chambers $(I=300 \mathrm{~mm} ; \mathrm{w}=245 \mathrm{~mm} ; \mathrm{h}=328 \mathrm{~mm}$ ) (Coulborne Instruments), each equipped with a pellet dispenser and a microliter injection pump, were used for the morphine self-administration and extinction studies. A catheter was connected to the rat and held in place with a spring-tether system, and a rotating swivel, which allowed the animals to move freely inside the chamber. Two levers placed $14 \mathrm{~cm}$ apart were available throughout all the sessions, one of them inactive. Due to a technical issue with the MedState program, the responses of the inactive lever were not recorded.

\section{4 - Experimental protocol (Fig. 1)}

\subsection{1 - Lever press instrumental training}

At the beginning of the experiment, all the rats received daily instrumental training sessions with food pellets as reinforcers (grain-based rodent tablet, Testdiet ${ }^{\mathrm{TM}}$ ) on a fixed ratio 1 schedule, facilitating the acquisition of self-administration behavior. During this training, the rats had restricted access to food (14 grams/day). The sessions lasted 30 minutes and 
continued until the animals developed a robust lever press behavior (at least 100 lever presses in three consecutive training sessions).

\subsection{2 - Surgery}

Rats were anesthetized with an isoflurane/oxygen mixture (5\% isoflurane during induction; $2 \% \pm 0.5 \%$ for maintenance), and a polyvinylchloride catheter $(0,16 \mathrm{~mm}$ i.d.) was inserted into the right jugular vein of the animal approximately at the level of the atrium and secured there with silk thread knots. The catheter was fixed subcutaneously around the neck, exiting the skin at the midscapular region. A pedestal of dental cement was then mounted on the skull of the rat in order to attach the tethering system. After surgery, the rats were allowed to recover for 7 days and a nonsteroidal anti-inflammatory drug (NSAID) (meloxicam Metacam $^{\text {TM }}: 15$ drops of a $1.5 \mathrm{~g} / \mathrm{ml}$ solution per $500 \mathrm{ml}$ of water) was added to the drinking water. Until the end of the self-administration procedure, the catheters were flushed daily with a sterile saline solution containing sodium heparin $(100 \mathrm{lU} / \mathrm{ml})$ and gentamicin $(1 \mathrm{mg} / \mathrm{ml})$ to maintain catheter patency and to prevent infections.

\subsection{3 - Morphine self-administration}

A week after recovery from surgery, the rats underwent 19 daily sessions of morphine self-administration. During the dark phase of the light cycle, for 12 hours (starting at $8 \mathrm{pm}$ ) rats were allowed daily access to morphine $(1 \mathrm{mg} / \mathrm{kg}$ in a sterile saline $-0.9 \% \mathrm{NaCl}$ - solution) or its vehicle alone under a fixed-ratio 1 reinforced schedule. During these sessions, one active lever press resulted in morphine infusion $(1 \mathrm{mg} / \mathrm{kg}$ morphine in saline solution delivered over 10 
seconds) followed by a 10 second time-out. A light cue located above the active lever indicated the availability of the drug, only being turned off during drug delivery, time out and at the end of each session. A limit of 50 infusions per session was set in order to avoid overdosing. One day after the last session, two groups of rats were sacrificed (VhSA, $n=10 ; M S A, n=10$ ), and their brains were processed and stored.

\subsection{4 - Extinction training}

The remaining rats were given 15 daily sessions of extinction training using the same self-administration protocol, although in this phase all the rats received saline injections instead of morphine. One day after the last extinction session, the two remaining groups of rats (VhEx, $n=8 ; M E x, n=8)$ were sacrificed, and their brains processed and stored.

\section{5 - Sample processing}

On the day of the sacrifice, the rats were decapitated and with the help of a brain matrix, $1 \mathrm{~mm}$ thick coronal slices were obtained at approximately $4.2 \mathrm{~mm}$ anterior from bregma for the prefrontal cortex, at approximately $3.10 \mathrm{~mm}$ posterior from bregma for the amygdala and at approximately $1.70 \mathrm{~mm}$ posterior from bregma for the PFC. With the help of two dissecting lancet-shaped needles, the amygdala (mainly the basolateral amygdala - BLA, although some marginal amounts of the adjacent central amygdala might have been included in some cases), the NAcc (both shell and core) and the prefrontal cortex (mostly the orbitofrontal cortex, OFC, although some marginal amounts of the agranular insular cortex might have been included in some cases) were dissected according to the Paxinos and Watson 
atlas (Franklin and Paxinos, 2007) (see Fig. 2). All the surfaces and tools used for dissection were sterilized and treated with RNAseZap ${ }^{\circledR}\left(\right.$ Ambion $\left.^{\mathrm{TM}}\right)$, and all the steps were carried out with caution to maintain RNA integrity. The tissue samples from one hemisphere (randomized) were preserved overnight at $4 \stackrel{\circ}{\circ} \mathrm{C}$ in $\operatorname{RNAlater}^{\circledR}\left(\mathrm{Ambion}^{\mathrm{TM}}\right)$ and then stored at $-70 \stackrel{\circ}{ } \mathrm{C}$ in RNAlater $^{\circledast}$ for later RT-qPCR analysis. The samples of the other hemisphere were snap frozen with dry ice and stored at $-70^{\circ}$ for western blot analysis.

\section{6 - RT-qPCR analysis}

The samples stored in RNAlater ${ }^{\circledR}$ were homogenized in QIAzol lysis reagent (QIAgen) using a pellet pestle. The total RNA was extracted and precipitated using the chloroform, isopropanol and ethanol method (Chomczynski and Sacchi, 1987) with glycogen as a carrier. The precipitate was dissolved in RNAse free water, and the concentration and RNA integrity (as indexed by the RIN value) was assessed in a bioanalyzer (Agilent 2100). The RNA concentration in each sample was adjusted by adding RNAse free water and to avoid genomic DNA contamination, DNAse digestion was performed (DNAse I, Amplification Grade, Invitrogen) following the manufacturer's instructions. Finally, the samples were retrotranscribed using a commercial kit (Biorad iScript ${ }^{\mathrm{TM}}$ cDNA Synthesis Kit). PCR assays were performed on a real time PCR detection system (CFX9600, Biorad) with a SSO Advanced SYBR mix (Biorad) using the primers indicated in the supplementary materials section. We ran duplicates of all the samples along with a no-template control and a no-RT control. We discarded the data of any assay with an unusual amplification or melt curve, if the difference between them was 
between duplicates was higher than one cycle. The relative expression of each gene calculated as described in Pfaffl, 2001 using Gapdh as a reference gene and the reaction efficiencies were obtained using LinRegPCR software (Ruijter et al., 2009), and normalized respect to the group VhSA.

\section{7 - Western blotting}

The tissue samples were homogenized using a pellet pestle in 10 volumes of lysis buffer: 50mM HEPES [pH7.5], $320 \mathrm{mM}$ sucrose, (Complete ${ }^{\mathrm{TM}}$ EDTA-free, Roche) protease inhibitors, and phosphatase inhibitors (PHOStop ${ }^{\mathrm{TM}}$, Roche). The resulting homogenate was centrifuged at $2000 \mathrm{~g}$ and at $4 \stackrel{\circ}{ } \mathrm{C}$ for 10 minutes, the supernatants were recovered and their protein concentration was assessed using the Bradford assay (Bio-Rad Protein Assay). The protein extracts $(3 \mu \mathrm{g})$ were mixed with 6 X Laemmli buffer and loaded onto $8 \%$ SDS-PAGE gels, resolved by electrophoresis and transferred to PVDF membranes. After blocking non-specific interactions with 5\% BSA for one hour, the membranes were probed overnight with the primary antibodies (see supplementary materials) that were then recognized with a horseradish peroxidase-conjugated secondary antibody (see supplementary materials). Antibody binding was visualized by chemiluminescence (ECL Plus Western Blotting Substrate, Pierce $\left.^{\mathrm{TM}}\right)$. As a control for protein loading, we measured the total protein loaded by adding 2,2,2-trichloroethanol to the gels prior to polymerization (final concentration $0.5 \% \mathrm{v} / \mathrm{v}$ : Ladner et al., 2004), and after resolving the gel, it was excited with an UV transilluminator and the fluorescence emitted was measured. We used a CCD based detector (Amersham Imager 600) 
to capture both the chemiluminiscence and the UV/fluorescence images, and the ImageJ software to analyze and quantify them. When necessary, antibodies were stripped using a harsh stripping protocol ("Stripping for reprobing": Abcam ${ }^{\circledR}$ ).

\section{8 - Statistical analysis}

The data obtained from the self-administration and extinction experiments were analyzed using repeated measures ANOVA. The analysis of the self-administration data had Sessions as a within-subject factor, and Treatment (Morphine-M- or Vehicle-Vh-) and Phase (Self-administration-SA- or Extinction-Ex-) as between-subject factors. The factor Phase was included in order to verify that there were no differences in self-administration behaviour (i.e. that the self-administration curves were comparable) between the rats used to analyse selfadministration effects and those used to analyse extinction-related alterations. In the analysis of the extinction behavioral data, we only examined the effects of Treatment (between-subject factor) and Sessions (within-subjects factor). The degrees of freedom were adjusted by applying the Greenhouse-Geisser correction when the sphericity assumption was violated.

To analyze the biochemical assays two-way ANOVAs were performed with two between-subject factors: Treatment and Phase. When the required assumptions for ANOVA were not met, logarithmic, square root or reciprocal transformations were applied. If the assumptions were still violated, a Kruskal-Wallis test was performed followed by a multiple comparison of mean rank sums with VhSA as the control condition including a Bonferroni correction to the p-values (Conover, 1999). 
Effect sizes were calculated for all the significant results, eta squared for the ANOVAs $\left(\eta^{2}\right)$, generalized eta squared for the repeated measures ANOVAs $\left(\eta_{G}{ }^{2}\right)$ (Bakeman, 2005) and chi squared for Kruskal-Wallis analyses.

2.9 - Software

The statistical analyses were performed using SPSS 24 (IBM) and the level of significance was set to $\alpha=0.05$ (uncorrected). The non-parametric multiple comparisons of groups were implemented in $R$, using the kwManyOneConoverTest function of the PMCMRPlus package (https://CRAN.R-project.org/package=PMCMRplus) by Thorsten Pohlert. All the graphs were designed using the PRISM 6 software (GraphPad Software, Inc).

3 - Results

3.1 - Behavioral data

All the animals achieved a high number of active lever presses during the acquisition phase, probably due to the previous autoshaping training (Fig. 1). Subsequently, the rats that received saline lowered the rate of active lever pressing, whereas the number of active lever presses of the rats that received morphine remained high. During the first extinction session, there was a surge in the number of active lever presses in the rats of the MEx group, although this decreased gradually in the following sessions until it reached values similar to those of the VhEx group. The two way-repeated measures ANOVA showed a significant effect of the Sessions factor $\left(\boldsymbol{F}_{\mathbf{7 . 3 4 , 2 2 7 . 6 3}}=\mathbf{3 . 9 4}, \mathbf{p}<\mathbf{0 . 0 0 1}, \boldsymbol{\eta}_{\mathrm{G}}{ }^{2}=\mathbf{0 . 0 7}\right)$. We also found a significant effect of the Treatment factor $\left(\mathbf{F}_{1,31}=\mathbf{7 3}, \mathbf{4 2}, \mathbf{p}<\mathbf{0 . 0 0 1}, \eta^{\mathbf{2}}=\mathbf{0 . 7}\right)$ suggesting that MSA animals pressed more the 
active lever than VhSA rats over the course of the self-administration sessions. We did not find any significant Treatment* Phase interaction $\left(\mathbf{F}_{\mathbf{1 , 3 1}}=\mathbf{0 , 4 2 5}, \mathbf{p}=\mathbf{0 . 5 2}, \boldsymbol{\eta}^{\mathbf{2}} \mathbf{\mathbf { 0 . 0 0 4 }}\right)$ or any effect of the Phase factor $\left(\mathbf{F}_{1,31}=\mathbf{0}, \mathbf{2 7 6}, \mathrm{p}=\mathbf{0 . 6}, \boldsymbol{\eta}^{\mathbf{2}}=\mathbf{0 . 0 0 2}\right)$. Therefore, it was concluded that the groups that underwent extinction performed similarly to their counterparts during the self-administration procedure. Regarding the extinction session data, we found a significant effect of the Sessions factor $\left(\mathbf{F}_{5.71,74,28}=\mathbf{3}, \mathbf{6 7}, \mathbf{p}=\mathbf{0 . 0 0 3}, \boldsymbol{\eta}_{\mathrm{G}}{ }^{\mathbf{2}}=\mathbf{0 . 1 7}\right)$. We also found a significant effect of the Treatment factor $\left(F_{1,13}=\mathbf{1 2 . 0 2}, \mathbf{p}=\mathbf{0 . 0 0 4}, \eta^{2}=\mathbf{0 . 4 8}\right)$ for the average values throughout the extinction sessions (see Fig. 1). To test whether the rats in the MEx group had extinguished the morphine selfadministration behavior, we compared the mean number of active lever presses during the last three days of extinction in the MEx and VhEx groups. Importantly, no significant differences were observed between these groups of rats $\left(t_{14}=-1.71, p>0.05\right)$.

\section{2 - Gene expression}

Most of the RIN values obtained ranged from 7 to 9 . In some very rare exceptions we obtained lower values, but in those cases we verified that the Cts of the GAPDH expression were in the same range as those of the other samples in the group. In the amygdala, the gene expression analysis identified a significant effect of the treatment on the expression of the Regulatory Associated Protein of MTOR Complex 1 (Rptor) $\left(\mathrm{F}_{1,28}=5.57, \mathbf{p}=\mathbf{0 . 0 2 5}, \eta^{2}=0.16\right)$ and the Eukaryotic Translation Initiation Factor 4E Binding Protein 2 (Eif4ebp2) $\left(F_{1,28}=4.28, \mathbf{p}=\mathbf{0 . 0 4 8}\right.$, $\eta^{2}=0.13$ : Table 1). The expression of these genes increased in the rats that self-administered morphine and this effect persisted even after extinction training. In this structure, we also 
found a main effect of the Phase factor on the expression of AKT Serine/Threonine Kinase 1 (Akt1) $\left(\mathrm{F}_{1,28}=6.9, \mathbf{p}=\mathbf{0 . 0 1 4}, \eta^{2}=0.19\right)$ and the Insulin Like Growth Factor 2 Receptor (Igf2r) $\left(F_{1,28}=5.74, \mathbf{p}=\mathbf{0 . 0 2 4}, \eta^{2}=0.15\right)$. In both cases transcription was enhanced after the extinction sessions. Significant differences in the Insulin Receptor (Insr) expression were evident between the four groups $\left(\chi^{2}{ }_{3}=14.96, p<0.002\right)$ and the multiple comparison test showed that the VhSA rats expressed Insr more strongly than the MSA and VhEx rats.

Igf $2 r$ expression was also affected In the PFC by the Phase factor $\left(F_{1,26}=7.32, \mathbf{p}=\mathbf{0 . 0 1 2}\right.$, $\left.\eta^{2}=0.21\right)$, although its expression was weaker after the extinction sessions.

There were no statistically significant differences in the expression of any of the genes analyzed in the NAcc.

\section{3 - Phosphoprotein levels}

We did not find any significant effects of the Treatment on the phosphoproteins assessed in each of the brain areas examined. However, in the amygdala the Phase factor affected the levels of phospho-GSK-3 $\alpha(\operatorname{Ser} 21 / 9)\left(F_{1,28}=5.32, p=0.029, \eta^{2}=0.14\right)$ and the $68 \mathrm{kDa}$ band of phospho-PDK1 (Ser241) $\left(F_{1,29}=6.18, p=0.019, \eta^{2}=0.17\right)$. The levels of both these phosphoproteins were lower after the extinction sessions (Fig. 5).

\section{4 - Discussion}

We assessed the effects of morphine self-administration and the subsequent extinction of this behavior on the expression of several genes and on the levels of specific 
phosphorylated proteins of the mTOR signaling pathway in three brain areas related to reward learning and extinction: the amygdala, the NAcc and the prefrontal cortex.

The morphine self-administration program employed only affected the expression of the Rptor and Eif4ebp2 genes in the amygdala, an effect that persisted after extinction (Table 1). The Rptor gene encodes the regulatory-associated protein of mTOR (Raptor), a protein in the mTOR complex 1 (mTORC1), while the product of the Eif4ebp2 gene is the eukaryotic translation initiation factor 4E-binding protein 2 (EIF4EBP2), one of the downstream effectors of this complex (Shimobayashi and Hall, 2014). Raptor regulates mTOR kinase activity, and it also recruits mTORC1 substrates like the $\mathrm{S} 6$ kinases and EIF4E binding proteins like EIF4EBP2 (Hara et al., 2002; Kim and Sabatini, 2004; Ma and Blenis, 2009). The elF4EBP proteins in turn regulate EIF4E activity, which is responsible for the cap-dependent translation of mRNAs (Richter and Sonenberg, 2005). Our dissection of the amygdala mostly included the BLA, an area with an important role in conditioning learning given that it encodes the motivational value of the conditioned stimulus, either appetitive or aversive (Everitt et al., 2003). The BLA also has a role in the formation, retrieval and reconsolidation of drug-related memories (Luo et al., 2013). Indeed, c-Fos activity in the BLA is enhanced in rats showing CPP or conditioned place aversion (CPA) to morphine (Guo et al., 2008). Considering all this evidence together, the enduring increase in mTORC1 activity after morphine self-administration in the BLA (as suggested by the elevated transcription of the Rptor and Eif4ebp2 genes) could contribute to 
the stabilization of those morphine-related aversive and appetitive memories that persist even after extinction.

Another interesting result was the variation in Insr gene expression that decreases drastically after morphine self-administration relative to rats exposed to the vehicle alone (Table 1). The Insr gene encodes the insulin receptor, one of the upstream activators of the PI3K/Akt/mTOR pathway (Niswender et al., 2003; Taha and Klip, 1999). Moreover, morphine can also activate this pathway through $\mu$ opioid receptors (Law et al., 2000; Polakiewicz et al., 1998). It is plausible that our results could reflect the opioid inhibition of insulin signaling due to a crosstalk between the downstream signaling pathways of both receptors, as shown previously in cell cultures (Li et al., 2003). These results are also consistent with the evidence that a chronic morphine regime downregulates the insulin receptor substrate 2 (IRS2)-Akt signaling pathway in the ventral tegmental area (Russo et al., 2007). This dampened endogenous insulin signaling might contribute to the development or expression of morphine withdrawal syndrome. Indeed, insulin administration reduces withdrawal symptoms in rats (Singh et al., 2015). Furthermore, rats that self-administered morphine did not display the decrease over time that vehicle treated rats did. This increase in the Insr might suggest recovery from withdrawal syndrome although direct evidence for this is lacking.

Previous works in the literature have suggested that SGK1 is up-regulated after opiate exposure. For example, Sgk1 mRNA expression is enhanced in whole brain lysates after chronic oxycodone administration, a $\mu$ opioid receptor agonist (Hassan et al., 2009). 
Elsewhere, Sgk1 mRNA levels and activity was seen to increase in the VTA after 7 days of passive morphine administration (i.p. 15mg/kg: Heller et al., 2015) and chronic morphine administration passively increases mTORC1 activity in the VTA, while decreasing that of mTORC2. Such treatment also decreased the soma size of VTA dopaminergic neurons, an effect that increased cell activity but that decreased dopamine output in the NAcc shell. These effects were blocked by overexpressing Rictor in the VTA, indicating that reduced mTORC2 activity mediates these adaptations (Mazei-Robison et al., 2011). SGK1 activation is mediated by the mTORC2 complex (García-Martínez and Alessi, 2008), and has previously been shown to play an important role in spatial memory consolidation (Lee et al., 2006; Tsai et al., 2002) and LTP (Ma, 2006). In spite of all these data, we only observed a marginal increase of Sgk1 mRNA expression (in all the brain areas studied) that did not reach statistical significance, suggesting a crucial effect for contingency in the effects of opiates on this mTORC2 effector (Table 1).

We also found changes independent of the treatment but that rather reflected the experimental phase. The Akt1 and Igfr2 genes were more strongly expressed in the amygdala in the groups that underwent extinction training, even in the rats that received a saline solution during the self-administration phase. As opposed to the amygdala, Igfr2 expression in the PFC was reduced in both groups after extinction (Table 1). These changes could reflect the natural regulation of these genes over the lifetime of the rats or maybe, they were a result of the experimental manipulations the rats were subjected to (surgery, handling, behavioral 
experiments...). Apart from the changes in gene expression, we also found variations in the phosphorylation of GSK-3 $\alpha$ (Ser21/9) and of the 68kDa isoform of PDK1 (Ser241), both of which changed after extinction in the two groups irrespective of their prior treatment (Fig. 5). The levels of both phosphoproteins decreased in the BLA after extinction, and those of phospho-GSK-3 $\alpha$ (Ser21/9) also tended to fall in the NAcc (Fig. 4).

There are some limitations to this study that need to be discussed. Firstly, we lose the registry of inactive lever presses. Although we have the data from the saline selfadministering rats that could account to some extent for non-specific lever presses, we may be overseeing potential effects of morphine self-administration in locomotor activity. The second limitation is that some effects of the previous food-reinforced operant conditioning on mTOR signaling might be affecting our results. This possibility nonetheless seems unlikely because the mTOR pathway is not involved in food reward seeking (Wang et al., 2010). In spite of these limitations, our findings open the door to new experiments using pharmacological or genetic manipulations of the mTOR pathway in the regions studied here that will provide a more definite evidence for the causal involvement of this pathway in the rewarding actions of morphine and in the extinction of morphine-related behaviours.

\section{5 - Concluding remarks}

In this study, we have addressed the putative effects of morphine self-administration and extinction on several elements of the mTOR pathway. Of the three areas studied, most of the significant results were found in the amygdala. The role of this area in the processes of 
drug addiction and relapse is well known but to our knowledge, no one has previously observed the potential involvement of the mTOR pathway in this limbic structure. The genes and phosphoproteins identified are mainly involved in regulating protein synthesis, and they may also be recruited during memory formation and reconsolidation, concurring with earlier data. In the light of these findings, it would be interesting to more directly study the therapeutic value of this signaling pathway in opioid-related disorders.

\section{6 - Acknowledgements}

This research was funded by the Spanish Ministerio de Economía y Competitividad (Project PSI2016-80541-P); the Ministerio de Sanidad, Servicios Sociales e Igualdad (Red de Trastornos Adictivos- Project RTA-RD16/020/0022 of the Instituto de Salud Carlos III; and the Plan Nacional sobre Drogas, Project 20161073); the Dirección General de Investigación de la Comunidad de Madrid (Project S-2011/BMD-2308, Programa de Actividades I+D+I CANNAB$\mathrm{CM}$ ); the UNED (Plan de Promoción de la Investigación); and the European Union (Project JUST/2013/DPIP/AG/4823-EU MADNESS). We also thank Rosa Ferrado, Luis Carrillo, Gonzalo Moreno and Alberto Marcos for their excellent technical assistance. 


\section{7 - References}

Abcam (n.d.) Stripping for reprobing. Available from:

http://www.abcam.com/ps/pdf/protocols/stripping for reprobing.pdf (accessed 24 February 2017).

Bailey J, Ma D and Szumlinski KK (2012) Rapamycin attenuates the expression of cocaineinduced place preference and behavioral sensitization. Addiction Biology, Blackwell Publishing Ltd 17(2): 248-258. Available from: http://doi.wiley.com/10.1111/j.13691600.2010.00311.x (accessed 22 February 2017).

Bakeman R (2005) Recommended effect size statistics for repeated measures designs. Behavior Research Methods, Springer-Verlag 37(3): 379-384. Available from: http://www.springerlink.com/index/10.3758/BF03192707 (accessed 22 November 2018).

Beckley JT, Laguesse S, Phamluong K, et al. (2016) The First Alcohol Drink Triggers mTORC1Dependent Synaptic Plasticity in Nucleus Accumbens Dopamine D1 Receptor Neurons. J. Neurosci. 36(3): 701-713.

Blommaart EFC, Luiken JJFP, Blommaart PJE, et al. (1995) Phosphorylation of ribosomal protein S6 is inhibitory for autophagy in isolated rat hepatocytes. Journal of Biological Chemistry 270(5): 2320-2326.

Brown AL, Flynn JR, Smith DW, et al. (2011) Down-regulated striatal gene expression for synaptic plasticity-associated proteins in addiction and relapse vulnerable animals. 
2011/01/06. Int J Neuropsychopharmacol 14(8): 1099-1110. Available from:

http://www.ncbi.nlm.nih.gov/entrez/query.fcgi?cmd=Retrieve\&db=PubMed\&dopt=Citati on\&list_uids=21205431.

Casadio A, Martin KC, Giustetto M, et al. (1999) A transient, neuron-wide form of CREBmediated long-term facilitation can be stabilized at specific synapses by local protein synthesis. Cell 99(2): 221-37. Available from:

http://www.ncbi.nlm.nih.gov/pubmed/10535740 (accessed 21 April 2017).

Chomczynski P and Sacchi N (1987) Single-step method of RNA isolation by acid guanidinium thiocyanate-phenol-chloroform extraction. Analytical Biochemistry 162(1): 156-159. Available from: http://linkinghub.elsevier.com/retrieve/pii/0003269787900212 (accessed 5 July 2017).

Conover WJ (1999) Practical nonparametric statistics. Wiley.

Costa-Mattioli M, Sossin WS, Klann E, et al. (2009) Translational control of long-lasting synaptic plasticity and memory. Neuron, Cold Spring Harbor Laboratory Press, Cold Spring Harbor, NY 61(1): 10-26. Available from: http://www.ncbi.nlm.nih.gov/pubmed/19146809 (accessed 3 May 2017).

Cui Yue, Zhang XQ, Cui Y., et al. (2010) Activation of phosphatidylinositol 3-kinase/Aktmammalian target of Rapamycin signaling pathway in the hippocampus is essential for the acquisition of morphine-induced place preference in rats. Neuroscience 171(1): 134- 
143. Available from: http://www.ncbi.nlm.nih.gov/pubmed/20826199 (accessed 18 January 2017).

Cunningham JT, Rodgers JT, Arlow DH, et al. (2007) mTOR controls mitochondrial oxidative function through a YY1-PGC-1alpha transcriptional complex. Nature 450(7170): 736-740.

Dayas C V, Smith DW and Dunkley PR (2012) An emerging role for the Mammalian target of rapamycin in 'pathological' protein translation: relevance to cocaine addiction. 2012/02/22. Front Pharmacol 3: 13. Available from: http://www.ncbi.nlm.nih.gov/entrez/query.fcgi?cmd=Retrieve\&db=PubMed\&dopt=Citati on\&list_uids=22347189.

Dos D. Sarbassov DD, Ali SM, Kim D-H, et al. (2004) Rictor, a Novel Binding Partner of mTOR, Defines a Rapamycin-Insensitive and Raptor-Independent Pathway that Regulates the Cytoskeleton. Current Biology 14(14): 1296-1302. Available from: http://www.ncbi.nlm.nih.gov/pubmed/15268862 (accessed 20 January 2017).

Düvel K, Yecies JL, Menon S, et al. (2010) Activation of a metabolic gene regulatory network downstream of mTOR complex 1. Molecular Cell 39(2): 171-183.

Everitt BJ, Cardinal RN, Parkinson JA, et al. (2003) Appetitive behavior: impact of amygdaladependent mechanisms of emotional learning. 2003/05/02. Annals of the New York Academy of Sciences 985: 233-250. Available from: http://www.ncbi.nlm.nih.gov/entrez/query.fcgi?cmd=Retrieve\&db=PubMed\&dopt=Citati 
on\&list_uids=12724162.

Franklin K and Paxinos G (2007) The Mouse Brain in Stereotaxic Coordinates, Third Edition. San Diego: Academic Press.

Gao Y, Peng S, Wen Q, et al. (2014) The mammalian target of rapamycin pathway in the basolateral amygdala is critical for nicotine-induced behavioural sensitization. The International Journal of Neuropsychopharmacology, Oxford University Press 17(11): 1881-1894. Available from: https://academic.oup.com/ijnp/articlelookup/doi/10.1017/S1461145714000650 (accessed 14 March 2018).

Guo N, Garcia MM and Harlan RE (2008) A morphine-paired environment alters c-Fos expression in the forebrain of rats displaying conditioned place preference or aversion. Behavioral Neuroscience, American Psychological Association 122(5): 1078-1086. Available from: http://doi.apa.org/getdoi.cfm?doi=10.1037/a0012595 (accessed 16 May 2017).

Hara K, Maruki Y, Long X, et al. (2002) Raptor, a binding partner of target of rapamycin (TOR), mediates TOR action. Cell 110(2): 177-89. Available from: http://www.ncbi.nlm.nih.gov/pubmed/12150926 (accessed 10 May 2017).

James MH, Quinn RK, Ong LK, et al. (2016) Rapamycin reduces motivated responding for cocaine and alters GluA1 expression in the ventral but not dorsal striatum. European Journal of Pharmacology 784: 147-154. 
Kalivas PW and O'Brien C (2008) Drug addiction as a pathology of staged neuroplasticity.

Neuropsychopharmacology 33(1): 166-180. Available from:

http://www.ncbi.nlm.nih.gov/entrez/query.fcgi?cmd=Retrieve\&db=PubMed\&dopt=Citati on\&list_uids=17805308.

Kauer JA and Malenka RC (2007) Synaptic plasticity and addiction. Nature reviews.

Neuroscience, Nature Publishing Group 8(11): 844-58. Available from:

http://dx.doi.org/10.1038/nrn2234 (accessed 12 March 2015).

Kim DH and Sabatini DM (2004) Raptor and mTOR: subunits of a nutrient-sensitive complex.

Current topics in microbiology and immunology 279: 259-70. Available from:

http://www.ncbi.nlm.nih.gov/pubmed/14560962 (accessed 10 May 2017).

Kwon C-H, Zhu X, Zhang J, et al. (2003) mTor is required for hypertrophy of Pten-deficient neuronal soma in vivo. Proceedings of the National Academy of Sciences 100(22): 1292312928. Available from: http://www.ncbi.nlm.nih.gov/pubmed/14534328 (accessed 20 January 2017).

Ladner CL, Yang J, Turner RJ, et al. (2004) Visible fluorescent detection of proteins in polyacrylamide gels without staining. Analytical Biochemistry 326(1): 13-20. Available from: http://linkinghub.elsevier.com/retrieve/pii/\$0003269703008017 (accessed 5 July 2017).

Law PY, Wong YH and Loh HH (2000) Molecular mechanisms and regulation of opioid receptor 
signaling. Annual review of pharmacology and toxicology 40(13): 389-430.

Li Y, Eitan S, Wu J, et al. (2003) Morphine Induces Desensitization of Insulin Receptor Signaling. Molecular and Cellular Biology 23(17): 6255-6266.

Lin J, Liu L, Wen Q, et al. (2014) Rapamycin prevents drug seeking via disrupting reconsolidation of reward memory in rats. International Journal of Neuropsychopharmacology 17(1): 127-136. Available from: http://ovidsp.ovid.com/ovidweb.cgi?T=JS\&CSC=Y\&NEWS=N\&PAGE=fulltext\&D=psyc11\& $A N=2013-43199-$

012\%5Cnhttp://mcgill.on.worldcat.org/atoztitles/link?sid=OVID:psycdb\&id=pmid:\&id=doi :10.1017\%2FS1461145713001156\&issn=1461-

1457\&isbn $=\&$ volume $=17 \&$ issue $=1 \&$ spage $=127 \&$ pag.

Liu-Yesucevitz L, Bassell GJ, Gitler AD, et al. (2011) Local RNA Translation at the Synapse and in Disease. Journal of Neuroscience 31(45): 16086-16093. Available from: http://www.ncbi.nlm.nih.gov/pubmed/22072660 (accessed 3 May 2017).

Luo Y-X, Xue Y-X, Shen H-W, et al. (2013) Role of amygdala in drug memory. Neurobiology of Learning and Memory 105: 159-173. Available from: http://www.sciencedirect.com/science/article/pii/S1074742713001093 (accessed 16 May 2017).

Lüscher C and Malenka RC (2011) Drug-Evoked Synaptic Plasticity in Addiction: From Molecular 
Changes to Circuit Remodeling. Neuron.

Ma XM and Blenis J (2004) Molecular mechanisms of mTOR-mediated translational control. Nature Reviews: Molecular Cell Biology 5(10): 827-835.

Ma XM and Blenis J (2009) Molecular mechanisms of mTOR-mediated translational control. Nature Reviews Molecular Cell Biology, Nature Publishing Group 10(5): 307-318. Available from: http://www.nature.com/doifinder/10.1038/nrm2672 (accessed 12 May 2017).

Mazei-Robison MS, Koo JW, Friedman AK, et al. (2011) Role for mTOR signaling and neuronal activity in morphine-induced adaptations in ventral tegmental area dopamine neurons. 2011/12/27. Neuron 72(6): 977-990. Available from:

http://www.ncbi.nlm.nih.gov/entrez/query.fcgi?cmd=Retrieve\&db=PubMed\&dopt=Citati on\&list_uids=22196333.

McLellan AT, Lewis DC, O’Brien CP, et al. (2000) Drug Dependence, a Chronic Medical Illness. JAMA, American Medical Association 284(13): 1689. Available from: http://jama.jamanetwork.com/article.aspx?doi=10.1001/jama.284.13.1689 (accessed 20 April 2017).

Narita M, Akai H, Kita T, et al. (2005) Involvement of mitogen-stimulated p70-S6 kinase in the development of sensitization to the methamphetamine-induced rewarding effect in rats. Neuroscience 132(3): 553-560. 
Neasta J, Barak S, Hamida S Ben, et al. (2014) mTOR complex 1: a key player in neuroadaptations induced by drugs of abuse. Journal of neurochemistry 130(2): 172-84.

Niswender KD, Gallis B, Blevins JE, et al. (2003) Immunocytochemical Detection of Phosphatidylinositol 3-kinase Activation by Insulin and Leptin. Journal of Histochemistry \& Cytochemistry 51(3): 275-283. Available from:

http://www.ncbi.nlm.nih.gov/pubmed/12588955 (accessed 8 May 2017).

Pearce LR, Komander D and Alessi DR (2010) The nuts and bolts of AGC protein kinases. Nature reviews. Molecular cell biology 11(1): 9-22. Available from:

http://www.nature.com/doifinder/10.1038/nrm2822 (accessed 20 January 2017).

Pfaffl MW (2001) A new mathematical model for relative quantification in real-time RT-PCR. Nucleic acids research, Oxford University Press 29(9): e45. Available from: http://www.ncbi.nlm.nih.gov/pubmed/11328886 (accessed 16 July 2018).

Polakiewicz RD, Schieferl SM, Gingras AC, et al. (1998) mu-Opioid receptor activates signaling pathways implicated in cell survival and translational control. The Journal of biological chemistry 273(36): 23534-41. Available from:

http://www.ncbi.nlm.nih.gov/pubmed/9722592 (accessed 17 January 2017).

Porstmann T, Santos CR, Griffiths B, et al. (2008) SREBP Activity Is Regulated by mTORC1 and Contributes to Akt-Dependent Cell Growth. Cell Metabolism 8(3): 224-236.

Richter JD and Sonenberg N (2005) Regulation of cap-dependent translation by elF4E inhibitory 
proteins. Nature 433(7025): 477-480. Available from:

http://www.ncbi.nlm.nih.gov/pubmed/15690031 (accessed 17 May 2017).

Ruijter JM, Ramakers C, Hoogaars WMH, et al. (2009) Amplification efficiency: linking baseline and bias in the analysis of quantitative PCR data. Nucleic Acids Research 37(6): e45-e45. Available from: http://www.ncbi.nlm.nih.gov/pubmed/19237396 (accessed 23 January 2017).

Russo SJ, Bolanos CA, Theobald DE, et al. (2007) IRS2-Akt pathway in midbrain dopamine neurons regulates behavioral and cellular responses to opiates. 2006/12/05. Nature Neuroscience 10(1): 93-99. Available from:

http://www.ncbi.nlm.nih.gov/entrez/query.fcgi?cmd=Retrieve\&db=PubMed\&dopt=Citati on\&list_uids=17143271.

Schieke SM, Phillips D, McCoy JP, et al. (2006) The mammalian target of rapamycin (mTOR) pathway regulates mitochondrial oxygen consumption and oxidative capacity. The Journal of biological chemistry 281(37): 27643-52. Available from:

http://www.ncbi.nlm.nih.gov/pubmed/16847060.

Shi J, Jun W, Zhao L-Y, et al. (2009) Effect of rapamycin on cue-induced drug craving in abstinent heroin addicts. European Journal of Pharmacology 615(1-3): 108-112. Available from: http://www.ncbi.nlm.nih.gov/pubmed/19470385 (accessed 18 January 2017). 
Shimobayashi M and Hall MN (2014) Making new contacts: the mTOR network in metabolism and signalling crosstalk. Nature reviews. Molecular cell biology, Nature Publishing Group 15(3): 155-62. Available from: http://www.ncbi.nlm.nih.gov/pubmed/24556838.

Singh $\mathrm{P}$, Sharma B, Gupta S, et al. (2015) In vivo and in vitro attenuation of naloxoneprecipitated experimental opioid withdrawal syndrome by insulin and selective K $<$ inf $>$ ATP $<$ /inf $>$ channel modulator. Psychopharmacology 232(2): 465-475.

Stoica L, Zhu PJ, Huang W, et al. (2011) Selective pharmacogenetic inhibition of mammalian target of Rapamycin complex I (mTORC1) blocks long-term synaptic plasticity and memory storage. Proceedings of the National Academy of Sciences of the United States of America 108(9): 3791-3796. Available from:

http://www.ncbi.nlm.nih.gov/pubmed/21307309\%5Cnhttp://www.pnas.org/content/10 8/9/3791.full.pdf+html.

Taha C and Klip A (1999) The Insulin Signaling Pathway. The Journal of Membrane Biology, Springer-Verlag 169(1): 1-12. Available from: http://link.springer.com/10.1007/PL00005896 (accessed 8 May 2017).

Wang X, Luo Y -x., He Y -y., et al. (2010) Nucleus Accumbens Core Mammalian Target of Rapamycin Signaling Pathway Is Critical for Cue-Induced Reinstatement of Cocaine Seeking in Rats. Journal of Neuroscience 30(38): 12632-12641. Available from: http://www.ncbi.nlm.nih.gov/pubmed/20861369 (accessed 23 February 2017). 
Wu J, McCallum SE, Glick SD, et al. (2011) Inhibition of the mammalian target of rapamycin pathway by rapamycin blocks cocaine-induced locomotor sensitization. Neuroscience 172: 104-109. Available from: http://www.ncbi.nlm.nih.gov/pubmed/20977929 (accessed 22 February 2017).

Zhou J, Blundell J, Ogawa S, et al. (2009) Pharmacological inhibition of mTORC1 suppresses anatomical, cellular, and behavioral abnormalities in neural-specific Pten knock-out mice. The Journal of neuroscience : the official journal of the Society for Neuroscience 29(6): 1773-83. Available from: http://www.jneurosci.org/cgi/doi/10.1523/JNEUROSCI.568508.2009 (accessed 20 January 2017). 